\title{
TNF- $\alpha$ drives remodeling of blood vessels and lymphatics in sustained airway inflammation in mice
}

\author{
Peter Baluk, ${ }^{1}$ Li-Chin Yao, ${ }^{1}$ Jennifer Feng, ${ }^{1}$ Talia Romano, ${ }^{1}$ Sonia S. Jung, ${ }^{2}$ Jessica L. Schreiter, ${ }^{2}$ \\ Li Yan, ${ }^{2}$ David J. Shealy, ${ }^{2}$ and Donald M. McDonald ${ }^{1}$ \\ ${ }^{1}$ Cardiovascular Research Institute, Comprehensive Cancer Center, and Department of Anatomy, UCSF, San Francisco, California, USA \\ 2Department of Immunology and Department of Oncology, Centocor Research and Development Inc., Radnor, Pennsylvania, USA.
}

\begin{abstract}
Inflammation is associated with blood vessel and lymphatic vessel proliferation and remodeling. The microvasculature of the mouse trachea provides an ideal opportunity to study this process, as Mycoplasma pulmonis infection of mouse airways induces widespread and sustained vessel remodeling, including enlargement of capillaries into venules and lymphangiogenesis. Although the mediators responsible for these vascular changes in mice have not been identified, VEGF-A is known not to be involved. Here, we sought to determine whether TNF- $\alpha$ drives the changes in blood vessels and lymphatics in M. pulmonis-infected mice. The endothelial cells, but not pericytes, of blood vessels, but not lymphatics, were immunoreactive for TNF receptor 1 (TNF-R1) and lymphotoxin B receptors. Most TNF-R2 immunoreactivity was on leukocytes. Infection resulted in a large and sustained increase in TNF- $\alpha$ expression, as measured by real-time quantitative RT-PCR, and smaller increases in lymphotoxins and TNF receptors that preceded vessel remodeling. Substantially less vessel remodeling and lymphangiogenesis occurred when TNF- $\alpha$ signaling was inhibited by a blocking antibody or was silenced in Tnfr $1^{-/-}$mice. When administered after infection was established, the TNF- $\alpha-$ specific antibody slowed but did not reverse blood vessel remodeling and lymphangiogenesis. The action of TNF- $\alpha$ on blood vessels is probably mediated through direct effects on endothelial cells, but its effects on lymphangiogenesis may require inflammatory mediators from recruited leukocytes. We conclude that TNF- $\alpha$ is a strong candidate for a mediator that drives blood vessel remodeling and lymphangiogenesis in inflammation.
\end{abstract}

\section{Introduction}

A wide spectrum of changes in blood vessels occurs in inflammation. Acute inflammation is accompanied by reversible vasodilatation, increased blood flow, plasma extravasation, and leukocyte adhesion and transmigration. In chronic inflammation, characteristic of asthma, obstructive pulmonary disease, rheumatoid arthritis, psoriasis, and inflammatory bowel disease, blood vessels and lymphatic vessels proliferate and undergo remodeling with changes in structural, functional, and molecular phenotypes. As part of the remodeling, capillaries enlarge and transform into venules that contribute to leukocyte adhesion and migration (refs. 1-3 and J. Fuxe, unpublished observations). Lymphatic vessels not only sprout and proliferate but also enlarge and undergo phenotypic changes $(4,5)$.

Although much attention has been devoted to sprouting angiogenesis in cancer, less is known about the factors that govern vascular remodeling in inflammation. The microvasculature of the mouse trachea presents an opportunity to study such factors because it (a) has a regular segmented 2D architecture repeated between and over the tracheal cartilage rings; (b) can be subjected to short- and long-lasting inflammatory stimuli (6); and (c) is a site of angiogenesis, vascular remodeling, and lymphangiogenesis after infection by Mycoplasma pulmonis. A conspicuous early feature of vascular remodeling in the airways of mice with $M$. pulmonis infection is enlargement

Conflict of interest: S. Jung, J. Schreiter, L. Yan, and D. Shealy are past or present employees of Centocor Research and Development Inc.

Citation for this article: J. Clin. Invest. 119:2954-2964 (2009). doi:10.1172/JCI37626 of capillaries into venules $(1,7)$. The enlargement results from endothelial cell proliferation, not merely vasodilatation (8), but the mediators that drive this change are unknown.

Factors that promote vascular remodeling, angiogenesis, or lymphangiogenesis include members of the VEGF, angiopoietin, FGF, TNF- $\alpha$, and TGF families, hepatocyte growth factor, interleukins, and other cytokines. Several lines of evidence indicate that VEGF-A does not play an essential role in vascular remodeling after M. pulmonis infection. Inhibition of VEGF-A signaling by VEGF receptor-blocking antibodies does not decrease the response (5). Conditional overexpression of VEGF-A in the airways results in abundant sprouting angiogenesis but little vascular enlargement (6). In comparison, angiopoietin overexpression tends to mimic the remodeling $(9,10)$. Although blockade of VEGF-C signaling via VEGFR-3 receptors by function-blocking antibody prevents lymphangiogenesis almost entirely (5), it has no effect on blood vessel remodeling. Furthermore, unlike TNF- $\alpha$, VEGF-A is not upregulated in lungs after M. pulmonis infection (11-13). These observations, and evidence that TNF- $\alpha$ regulates many downstream changes in inflammation (14-17), prompted us to assess the role of TNF signaling in vascular remodeling and lymphangiogenesis after $M$. pulmonis infection.

TNF- $\alpha$ can promote angiogenesis in vivo $(18,19)$, but the mechanisms involved are controversial. We sought to determine whether TNF signaling drives the vascular remodeling and lymphangiogenesis in mouse airways after M. pulmonis infection, either by acting directly on endothelial cells or by inducing the production of other factors. To address these issues, we asked 5 questions: (a) What is the time course of vascular changes in mouse airways 

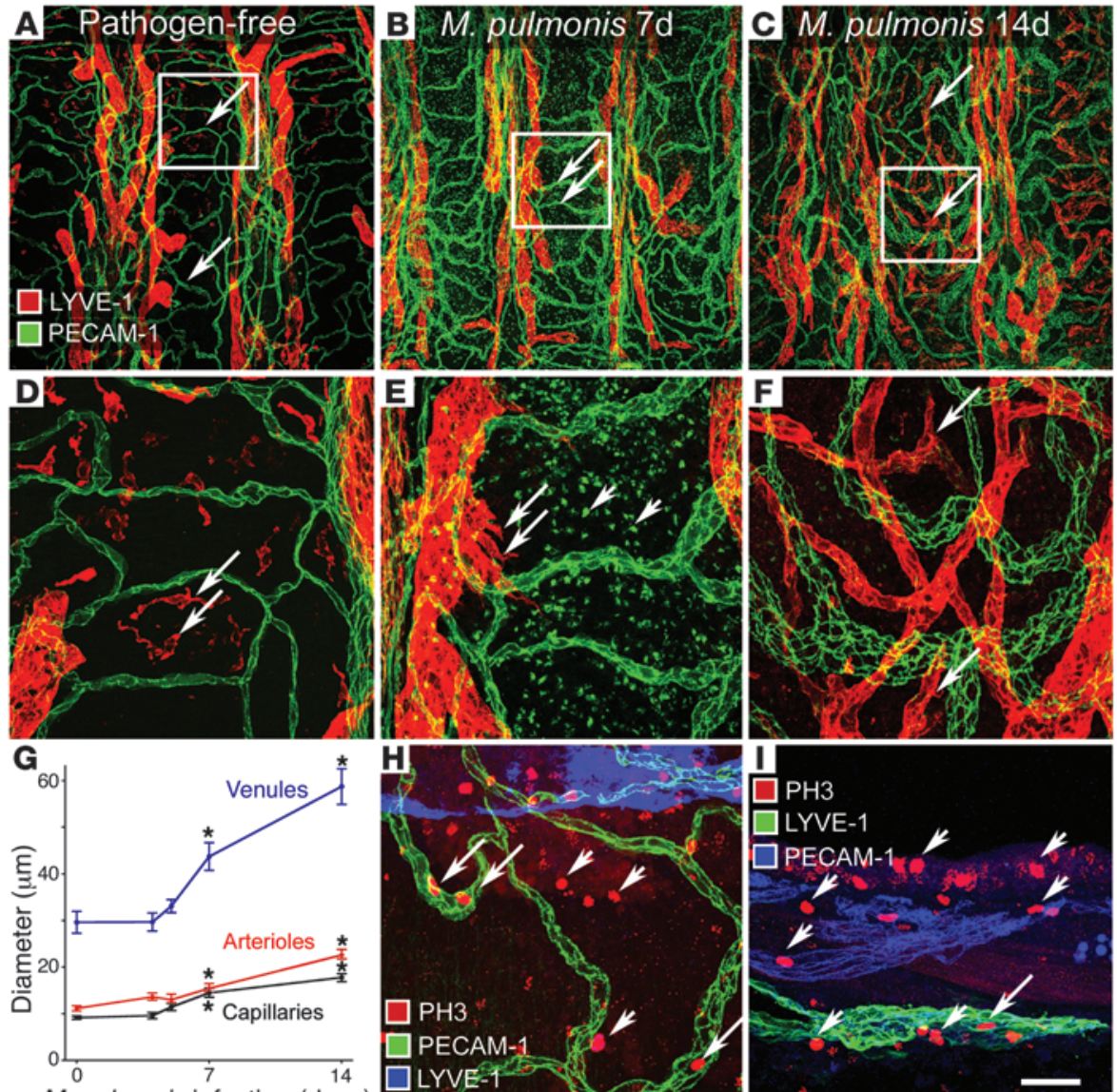

M. pulmonis infection (days)
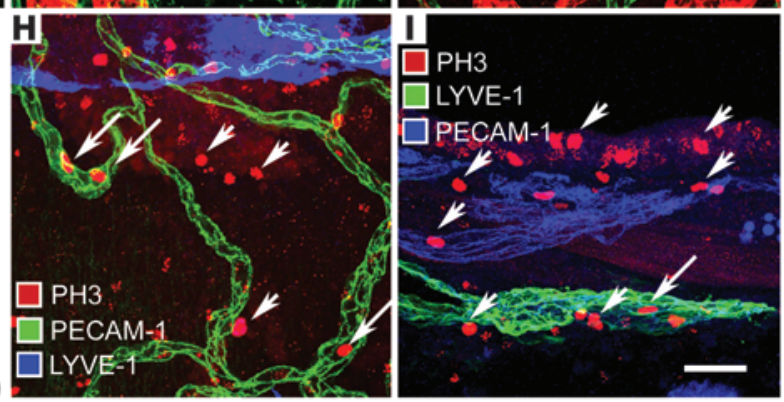

\section{Figure 1}

Time course of airway vessel changes after infection. (A) Low-magnification view of highly ordered blood vessels (green) and lymphatics (red) in a flat whole mount of pathogen-free C57BL/6 mouse trachea. Most blood vessels and lymphatics are arranged in arcades in mucosa between cartilage rings. Capillaries of relatively uniform caliber (arrows) cross cartilage, but lymphatics do not. (B) Widened capillaries (arrows) over cartilages 7 days after M. pulmonis infection. (C) At 14 days, blood vessels are larger and lymphatic sprouts (arrows) are more abundant. Boxed regions enlarged in D-F. (D) In pathogen-free mouse, LYVE-1 lymphatic sprouts are absent but some leukocytes (arrows) express LYVE-1. See also Supplemental Figure 1. (E) Vessel changes are accompanied by an influx of leukocytes, many stained for PECAM-1 (short arrows). Lymphatic sprouts are indicated by arrows. (F) Abundant lymphatic sprouts (arrows) and enlarged blood vessels. (G) Time course of changes in blood vessel diameter. ${ }^{*} P<0.05$ versus pathogen-free. Data are represented as means \pm SEM. $(\mathbf{H})$ Triple-stained for PECAM-1, phosphohistone $\mathrm{H} 3$ (PH3), a marker of dividing nuclei, and LYVE-1 at 7 days. PH3-labeled endothelial nuclei (arrows) and nonendothelial cells (short arrows). (I) Cross-section of 14-day infected trachea. Many dividing nuclei (red) are present in epithelium and in other mucosal cells (short arrows). Although several labeled nuclei appear to coincide with lymphatics or blood vessels, most are actually superimposed and few (arrows) are truly located in vessels (arrows) as determined by examination of individual confocal sections. Scale bars: $200 \mu \mathrm{m}$ (A-C, H, and I); $50 \mu \mathrm{m}$ (D-F).

after M. pulmonis infection? (b) Is the expression of TNF- $\alpha$ or its receptors increased after infection? If so, does the time course of changes in expression match the time course of remodeling of blood vessels and lymphatics? (c) Does expression of the TNF family members lymphotoxin A and lymphotoxin B or their receptors change after infection? (d) Are TNF receptors present on endothelial cells of blood vessels or lymphatics and does their distribution change after infection? (e) Can blood vessel remodeling or lymphangiogenesis after $M$. pulmonis infection be prevented or reversed by inhibition of TNF signaling? To answer these questions, we compared the amount and distribution of TNF- $\alpha$ expression in airways of pathogen-free and $M$. pulmonis-infected mice and examined the effect of blocking TNF signaling with a function-blocking antibody or by genetic deletion of TNF receptor 1 (TNF-R1). Using immunohistochemistry and quantitative RT-PCR (qRT-PCR) analysis, we found that TNF- $\alpha$ was strongly upregulated in airways after infection, but before the vascular remodeling and lymphangiogenesis began. TNF-R1 receptors were present on endothelial cells. The vascular changes were reduced by blocking TNF signaling but could not be reversed by treatment started 1 or 4 weeks after infection.

\section{Results}

Time course of vascular changes after M. pulmonis infection. The tracheal microvasculature of pathogen-free C57BL/6 mice was highly ordered and stereotyped. Arcades of blood vessels and lymphatics were arranged in the mucosa between the cartilage rings (Figure 1A). Only capillaries of relatively uniform caliber and almost no lymphatics crossed the cartilage rings in pathogen-free mice (Figure 1, A and D). All segments of the microvasculature enlarged in diameter over the first few weeks of $M$. pulmonis infection (Figure 1, B-G). Lymphatic sprouts, identified by lymphatic vessel endothelial hyaluronan receptor 1 (LYVE-1) staining, were present from the end of the first week of infection (Figure 1, B and E). By 14 days of infection, the regions of mucosa over cartilages contained enlarged blood vessels and lymphatic sprouts (Figure 1, C and F). Scattered LYVE-1-positive cells not connected to lymphatics did not express VEGFR-3, Prox1, or podoplanin (Supplemental Figure 1; supplemental material available online with this article; doi:10.1172/JCI37626DS1) and were probably macrophages (20-22). The vessel changes were accompanied by an influx of leukocytes, many of which stained for PECAM-1 immunoreactivity. Immunohistochemical staining for phosphohistone H3, a marker of mitotic nuclei, provided evidence of endothelial cell division after M. pulmonis infection. Phosphohistone H3-labeled endothelial nuclei of blood vessels and lymphatics were rare in pathogen-free mice (data not shown) but were abundant after day 7 of infection (Figure 1, H and I). Many dividing cells were also present in the airway epithelium and mucosa (Figure 1I). 

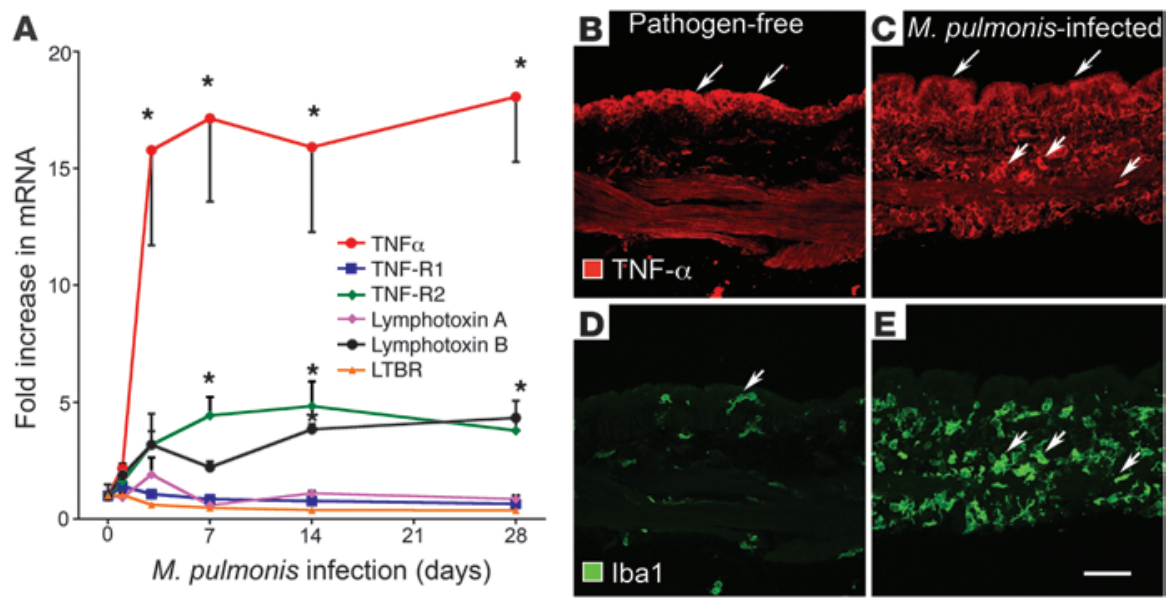

Figure 2

Expression of TNF family ligands and receptors in pathogen-free and $M$. pulmonis-infected mouse airways. (A) qRT-PCR. Fold increase in mRNA compared with pathogen free. ${ }^{*} P<0.05$ versus pathogen-free. Data are represented as means \pm SEM. (B-D) Confocal images of TNF- $\alpha$ and Iba1 immunoreactivity in cross-sections of (B and $\mathbf{D})$ pathogen-free and ( $\mathbf{C}$ and $\mathbf{E})$ infected tracheas. (B) Strongest TNF- $\alpha$ staining is mainly in epithelium (arrows) in pathogen-free mouse. (C) Strong TNF- $\alpha$ staining is more widely distributed after infection. Some leukocytes (short arrows) are strongly stained. (D and E) Iba1, a marker of macrophages and dendritic cells, is sparse in pathogen-free trachea (D) but widely scattered in leukocytes after infection (E). Scale bar: $50 \mu \mathrm{m}$.

Expression of TNF- $\alpha$ family members and receptors after infection. qRT-PCR showed that TNF- $\alpha$ expression increased rapidly after M. pulmonis infection. The 15 -fold increase at 3 days persisted for at least 4 weeks (Figure 2A). Notably, the increase in TNF- $\alpha$ expression after infection preceded the onset of blood remodeling. Expression of the TNF family members lymphotoxin A and lymphotoxin B increased only 2- and 4-fold (Figure 2A). Expression of TNF-R1 and lymphotoxin B receptor (LTBR) stayed relatively flat. TNF-R2 expression peaked at a 4-fold increase on day 14 (Figure 2A).

TNF- $\alpha$ immunoreactivity was moderate in the epithelium and respiratory smooth muscle of the trachea of pathogen-free mice (Figure 2, B and D). The amount and intensity of staining increased after infection, when macrophages and other leukocytes had strong immunoreactivity (Figure 2, C and E).

$T N F$ receptors on endothelial cells of blood vessels but not lymphatics. We determined the distribution of immunoreactivity for TNF-R1, TNF-R2, and LTBR in sections of pathogen-free and M. pulmonisinfected tracheas also stained with Iba1 immunoreactivity (23) as a marker for macrophages and dendritic cells (Supplemental Figure 2). TNF-R1 immunoreactivity was present on multiple cell types in pathogen-free mouse airways, notably on airway epithelial cells, smooth muscle, and vessels (Supplemental Figure 2, A-D). TNF-R2 immunoreactivity was found on immune cells (Supplemental Figure 2, E-H), but not on blood vessels or lymphatics. However, LTBR immunoreactivity was present on blood vessels (Supplemental Figure 2, I-L). In addition, to explore the distribution of TNF-R1 and LTBR immunoreactivity in more detail, we examined tracheas of pathogen-free mice in which vascular endothelial cells, pericytes, smooth muscle cells, and lymphatics were labeled (Figures 3 and 4 and Supplemental Figure 3). These experiments revealed that TNF-R1 (Figure 3, A-C) and LTBR (Figure 3, D-F) staining of endothelial cells of blood vessels was stronger in venules and capillaries than in arterioles and was weak in lymphatics (Figure 4). In tion-blocking antibody and in $\mathrm{Tn} f \mathrm{r}^{-/-}$mice (Figure 5E). We also confirmed that blood vessels and lymphatics of pathogen-free Tnfr $1^{-1-}$ mice were normal and essentially indistinguishable from those of pathogen-free WT mice (Supplemental Figure 4).

In an effort to identify which VEGF family member is responsible for the lymphangiogenesis, we analyzed pathogen-free and 14-day infected WT and Tnfr1 $1^{-/}$tracheas by qRT-PCR (Figure 5F). We found that mRNA for VEGF-C was increased in infected WT mice, but not in infected Tnfr $1^{-/-}$mice. Expression of VEGF-D and VEGF-A was not increased under these conditions (Figure 5F).

Blocking TNF signaling pharmacologically or genetically also reduced leukocyte influx into the airways and lungs (Figure 5, G-J). In infected WT mice, leukocytes accumulated in peribronchial and periarterial cuffs of bronchial-associated lymphoid tissue (BALT). In some mice, an entire lung (usually the left lung) was consolidated by leukocytes, and total lung weight almost doubled (93\% increase). After infection, the increase in lung weight was $72 \%$ less in WT mice treated with anti-TNF- $\alpha$ antibody and $66 \%$ less in Tnfr $1^{-/-}$mice. BALT was also less under these conditions.

Exaggerated vascular remodeling after infection of Tnfa $\mathrm{\alpha}^{-1-}$ mice. The effects of M. pulmonis infection in Tnf $\alpha^{-/-}$mice were initially expected to phenocopy the effects of the blocking antibody in WT mice or of genetic deletion of TNF-R1. Surprisingly, Tnf $\mathrm{C}^{-/-}$mice had more than $80 \%$ mortality, which was greatest on days 5-7 of infection; only a few survived to day 14 after infection with the same dose as WT mice or Tnfr $1^{-1-}$ mice $\left(10^{6} \mathrm{CFU}\right.$ M. pulmonis organisms). RT-PCR measurements of copy number of $M$. pulmonisspecific 16S rRNA (relative to $\beta$-actin) as an index of bacterial burden showed that tracheas of $\mathrm{Tnfa}^{-/-}$mice had 34-fold as many organisms as corresponding WT mice and 5-fold as many organisms as infected Tnfr $1^{-/-}$mice at 3 days of infection. No 16S rRNA expression was detected in pathogen-free mice. The increase in expression of TNF- $\alpha$ was not significantly different in airways of 

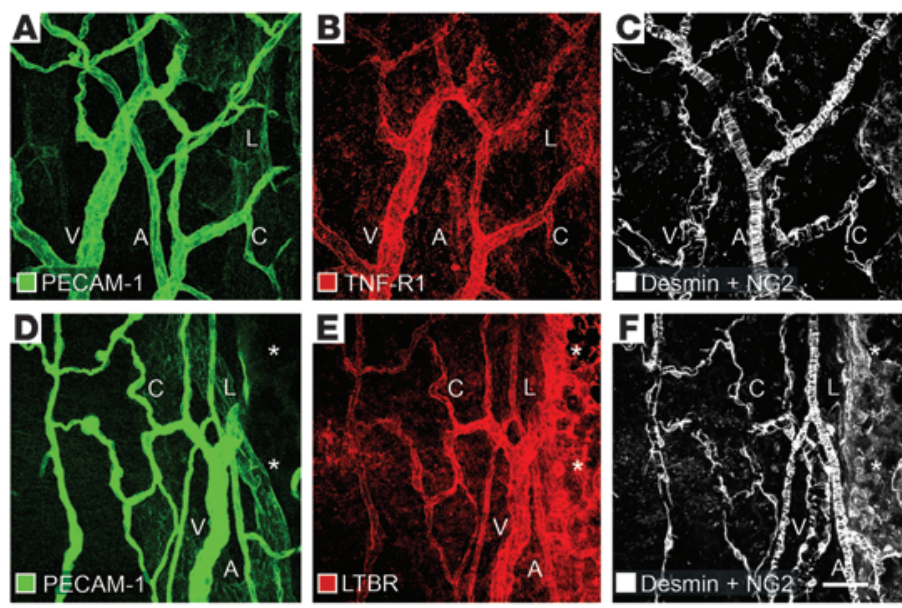

Figure 3

Distribution of TNF-R1 and lymphotoxin receptors on endothelial and periendothelial cells in tracheal whole mounts of pathogen-free mice. (A-C) TNF-R1 and (D-F) LTBR immunoreactivity. Endothelial cells stained with rat antimouse PECAM-1 antibody and pericytes/smooth muscle cells stained with desmin and NG2 antibodies. Vessels: arterioles (A); capillaries (C); venules (V); lymphatics (L, faintly stained). TNF-R1 and LTBR immunoreactivity is stronger in venules and capillaries than in arterioles and very weak in lymphatics. Both TNF-R1 and LTBR staining have smooth continuous contours of endothelial cells rather than the sharp discrete outlines of periendothelial cells. Pericytes and vascular smooth muscle cells have very weak TNF-R1 and LBTR staining in contrast with strong staining of respiratory smooth muscle (see also Supplemental Figure 3). Scattered diffuse staining for TNR-R1 and LBTR in other mucosal cells, with strong LBTR staining in tracheal cartilages $\left({ }^{*}\right)$. For additional analysis of TNF-R1 staining combined with other markers of blood and lymphatic endothelial cells and periendothelial cells, see Supplemental Figure 3. Scale bar: $50 \mu \mathrm{m}$.

3-day infected WT C57BL/6 and in the background stain for Tnfa- $\mathrm{F}^{-1}$ mice (B6129SF2/J; JAX strain 101045; $15.8 \pm 4$ - vs. $13.0 \pm 2$-fold increase relative to respective pathogen-free mouse; $n=7-8$ mice per group, $P>0.05)$. Surviving $\operatorname{Tn} f \alpha^{-/-}$mice were much sicker than WT mice, as reflected by severe blood vessel remodeling and lymphangiogenesis (Figure 6, A-C), leukocyte influx into lungs, and hypertrophy of bronchial lymph nodes. As with Tnfr $1^{-/-}$mice, blood vessels and lymphatics of pathogen-free $T n \mathrm{fa}^{-/-}$mice were essentially indistinguishable from those of pathogen-free WT mice (Supplemental Figure 4).

To discover whether other cytokines could compensate for the absence of TNF- $\alpha$, we performed qRT-PCR analysis on tracheas from pathogen-free and infected $T n f \alpha^{-/-}$and corresponding WT mice. These experiments were done at 3 days of infection, before most $T n \mathrm{fa}^{-/}$ mice succumbed. As expected, TNF- $\alpha$ expression was not detected in pathogen-free or infected Tnf $\alpha^{-/-}$mice (Figure 6D). Expression of lymphotoxin A and lymphotoxin B was increased in infected Tnfa ${ }^{-/-}$mice, and lymphotoxin A expression in infected $T n f \alpha^{-/-}$mice was about 2 -fold higher than in WT mice (Figure 6D). Expression of TNF-R2 was increased in infected WT and Tnf $\alpha^{-/-}$mice (probably on account of leukocyte influx), while TNF-R1 was significantly increased only in WT mice (Figure 6E). Expression of LTBRs was not significantly different between the groups. In general, the expression (in terms of copy number relative to $\beta$-actin) of the ligands TNF- $\alpha$, lymphotoxin A, and lymphotoxin B was much higher than that of their receptors, TNF-R1, TNF-R2, and LTBR (Figure 6, D and E).
Gene profiling. Additional gene-profiling studies showed that expression of almost half of the 84 target genes on TaqMan mouse immune gene arrays was increased or decreased more than 2 -fold after 3 days of $M$. pulmonis infection in WT, Tnfr $1^{-/-}$, or Tnf $\alpha^{-/-}$mice (Table 1). As expected, many genes for leukocyte markers, adhesion molecules, chemokines, cytokines, and their receptors were greatly upregulated in infected WT mice.

Notably, expression of TNF- $\alpha$, IL- $1 \alpha$, IL-1 $\beta$, and IL- 6 , and inducible nitric oxide synthase was increased, but surprisingly, expression of prostaglandin-endoperoxide synthase 2 (cyclooxygenase 2) and VEGF-A was not. The inflammatory monocyte/macrophage chemokines $\mathrm{Ccl} 2$, $\mathrm{Ccl} 3$, and $\mathrm{Cxcl} 10$ were also greatly increased, but not the receptor Ccr2. Expression of leukocyte adhesion molecules E selectin, P selectin, and VCAM was also increased.

Gene profiling also identified differences in mouse groups after infection (Table 1). Many genes increased less after infection in $\mathrm{Tnfr} \mathrm{1}^{-/-}$mice, consistent with the reduced remodeling. In infected Tnf $\alpha^{-/-}$mice, as expected, TNF- $\alpha$ expression was not detected. Ccl3, IL- $1 \alpha$, IL-1 $\beta$, and IL-6 expression was increased less than in infected WT mice. In addition to the increased levels of lymphotoxin A identified by qRT-PCR, gene arrays revealed increased expression of Ccl5, Ccl19, and suppressor of cytokine signaling 2 in infected $T$ n $\mathrm{fa}^{-1-}$ mice.

Lack of reversal of blood vessel remodeling or lymphangiogenesis after inhibition of TNF signaling. Blood-vessel remodeling (Figure 7A) and lymphangiogenesis (Figure 7B) after 1 week of infection were not reversed by 1 week of treatment, but further growth was reduced. Likewise, blood-vessel remodeling and lymphangiogenesis were not reversed by the anti-TNF- $\alpha$ antibody for the last 2 weeks of a 6 -week infection period, but further growth was reduced (Figure 7C). Growth of bronchial lymph nodes was stopped but not reversed by the anti-TNF- $\alpha$ antibody treatment during weeks 5 and 6 of infection (Figure 7D).

\section{Discussion}

Having found that remodeling of airway blood vessels in mice infected with $M$. pulmonis was not primarily driven by VEGF or by bFGF, we sought to identify the mediators involved. TNF- $\alpha$ seemed a reasonable candidate because in many pathological conditions, it is associated with vascular changes, is produced in inflamed airways, and stimulates angiogenesis in multiple settings. However, the role of TNF- $\alpha$ in vascular remodeling in airway inflammation has not been previously examined.

Blood vessels grow and change their shape by multiple mechanisms (24). In embryos, blood vessels form initially by vasculogenesis involving the coalescence of cells into a primitive branching vascular plexus, which subsequently expands by angiogenesis. In postnatal life, most new blood vessels arise by sprouting angiogenesis, in which endothelial tip cells sprout and endothelial stalk cells proliferate (25). Another kind of vessel growth is intussusceptive angiogenesis, e.g., in the pulmonary circulation, in which existing vessels divide internally and split into daughter vessels (26). Blood vessels also undergo remodeling, in which their characteristic phenotype changes, rather than their number. One example is arteriogenesis, in which fine diameter collateral vessels become arterioles $(27,28)$. In another type of vascular remodeling, capillaries enlarge and trans- 

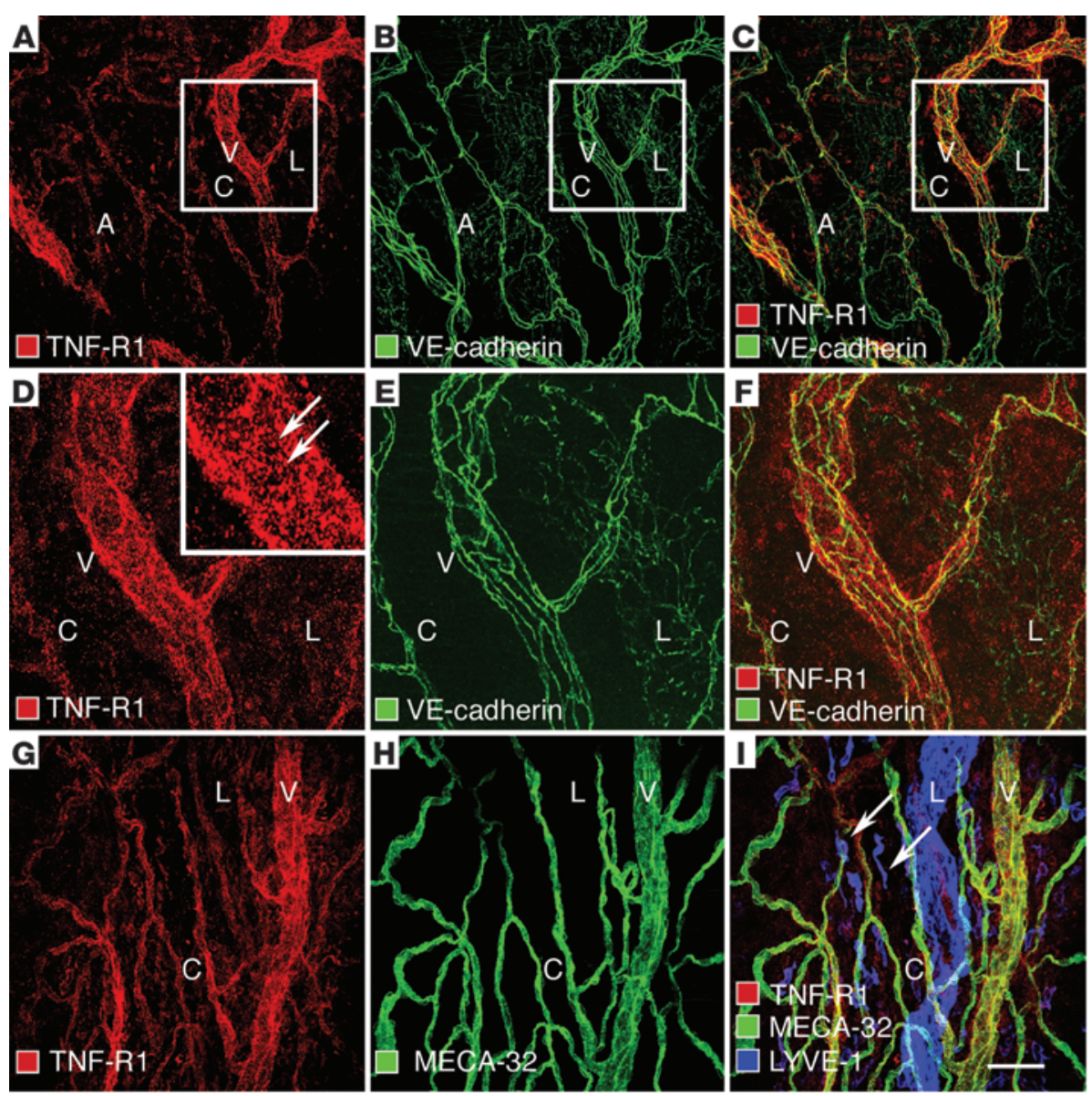

Figure 4

TNF-R1 immunoreactivity on endothelial cells of blood vessels. (A-F) Confocal images of pathogen-free mouse tracheas stained for TNF-R1 (red) and VE-cadherin (green) or (G-I) for MECA-32 and LYVE-1. Strong TNF-R1 immunoreactivity of venules, intermediate staining of capillaries, and weak staining of arterioles and lymphatics. Boxed regions in $\mathbf{A}-\mathbf{C}$ are enlarged in $\mathbf{D}-\mathbf{F}$. Inset in $\mathbf{D}$ shows punctate staining (arrows) of TNF-R1 in venular endothelial cells. (G-I) TNF-R1 immunoreactivity is weak or absent in LYVE-1 immunoreactive (blue) lymphatics and nonendothelial cells (arrows). Scale bars: $200 \mu \mathrm{m}$ (A-C); $50 \mu \mathrm{m}$ (D-I); $25 \mu \mathrm{m}$ (D, inset).

form into venules capable of plasma extravasation and leukocyte trafficking. This change, which is a prominent feature of M. pulmonis infection of the airways (1), is the focus of the present study. Several endothelial growth factors and signaling pathways have been proposed for other forms of angiogenesis, but to date there have been no convincing candidates for driving vascular enlargement.

In the present study, we took advantage of knockout and transgenic mice to examine the mechanism of vascular remodeling in more detail. Genetic background can influence the magnitude and type of angiogenesis that occurs in response to a stimulus $(29,30)$. Previously, we examined vascular remodeling in $\mathrm{C} 3 \mathrm{H}$ mice, which are unusually susceptible to $M$. pulmonis infection and have particularly severe vascular changes (1). M. pulmonis is a naturally occurring pathogen that commonly infects and remodels the respiratory tract of rodents housed under "conventional" nonbarrier conditions (31-33). Endothelial cell division, as shown by BrdU labeling, peaks in $\mathrm{C} 3 \mathrm{H}$ mice at 5 days of infection (8), demonstrating that the capillary enlargement occurs by endothelial cell division and is not simply vasodilatation. During the first 2 weeks of infection, vascular changes are qualitatively similar but less prominent in C57BL/6 mice (1). Phosphohistone $\mathrm{H} 3$ immunoreactive endothelial cells are present in all segments of the tracheal microvasculature of infected C57BL/6 mice. Phosphohistone H3-labeling studies also indicate that growth of lymphatics follows a similar paradigm of "tip cells and stalk cells" as used by endothelial sprouts of blood vessels (5). At later stages of infection, when BALT has accumulated, sprouting angiogenesis occurs in the airways of C57BL/6 mice (1). Thus, multiple vascular changes can occur in the same tissue, and multiple mediators are probably involved.

TNF- $\alpha$ has long been recognized as a master regulatory cytokine capable of initiating the inflammatory cascade by switching on many downstream genes, inducing expression of other cytokines and chemokines, signaling molecules and transcription factors, cell surface receptors and adhesion molecules, components of the coagulation system, apoptosis- and cell proliferationrelated genes, and other inflammatory response genes (17, 34-36). The present study examined the kinetics and cellular location of expression of TNF- $\alpha$, related family members, and receptors in infected C57BL/ 6 mouse airways.

Increased expression of TNF- $\alpha$ and lymphotoxin A has been reported in mouse lungs after $M$. pulmonis infection (11-13) but has not been previously examined from the perspective of vessel remodeling in the airways. In comparison with lungs, in which expression of TNF- $\alpha$ peaks within a few hours of infection and then declines to near baseline values $(11,13)$, TNF- $\alpha$ expression in the tracheas was sustained over the course of the disease. This difference may represent histological differences in cell populations in the trachea and the lung, a complex mixture of parenchymal alveolar tissues and intrapulmonary airways. Being able to measure TNF- $\alpha$ expression and assess vascular remodeling and lymphangiogenesis in the trachea strengthened the case for the involvement of TNF- $\alpha$ in vascular remodeling.

Among the chemokines induced by TNF- $\alpha$ are CCL2, CCL7, CXCL2, and CXCL5, which attract macrophages, neutrophils, and other leukocytes, which in their turn secrete further mediators that amplify the inflammatory cascade $(14,15,17,37)$. Likewise, TNF- $\alpha$ induces expression of E selectin, VCAM-1, and ICAM-1 in endothelial cells that mediate leukocyte adhesion and extravasation (36). In the present study, Taqman analysis confirmed that many cytokines (notably including IL-1), chemokines, adhesion molecules, and other inflammatory molecules 

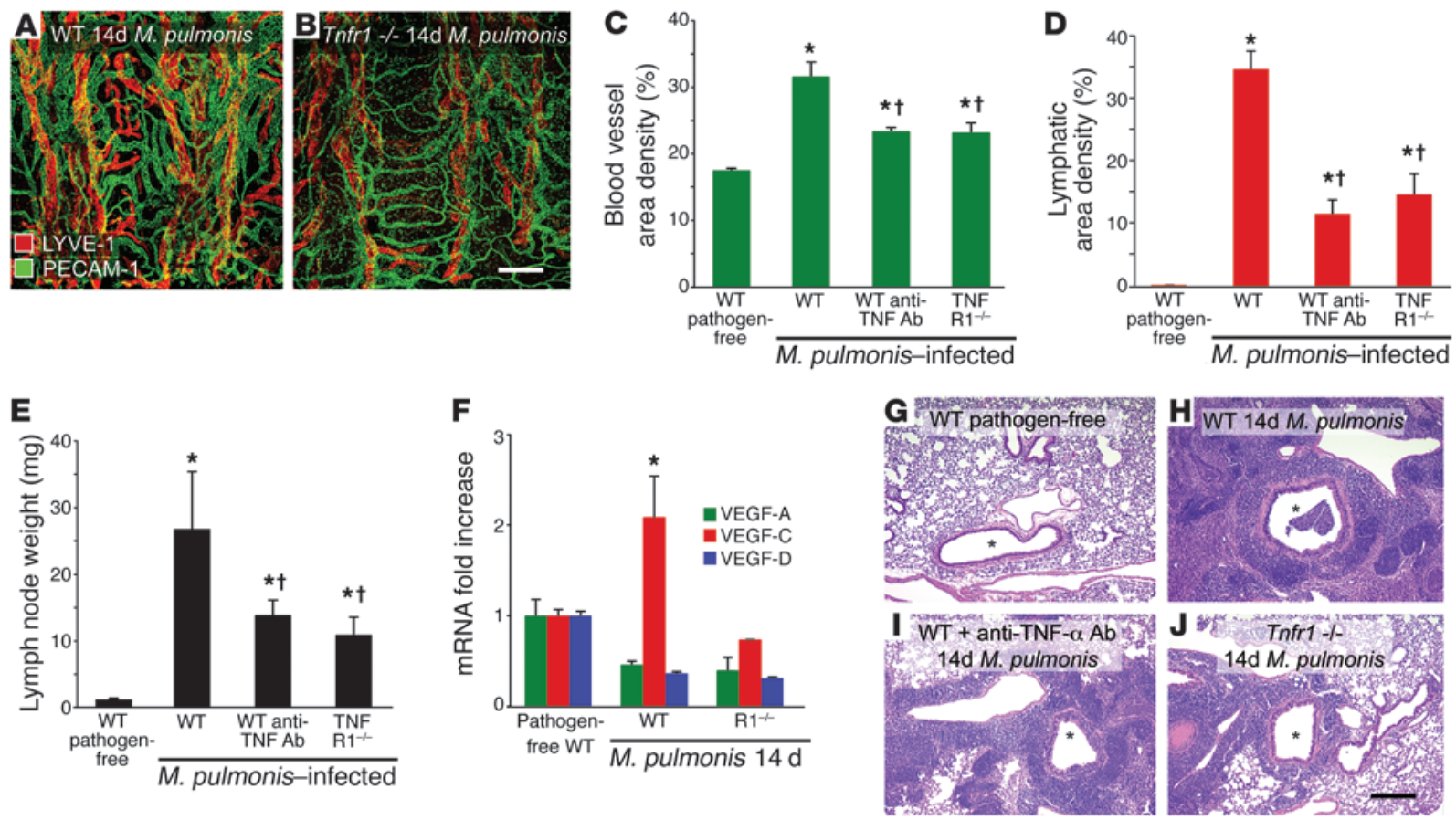

\section{Figure 5}

Blood vessel remodeling, lymphangiogenesis, and leukocyte influx after blocking TNF signaling. (A) Extensive blood vessel remodeling and lymphangiogenesis in trachea of WT 14-day M. pulmonis-infected mouse. (B) Little vascular remodeling or lymphatic growth in infected Tnfr1-/mouse. Scale bar: $200 \mu \mathrm{m}$. (C and D) Area density of blood vessels (C) and lymphatics (D) in WT mice treated with anti-TNF- $\alpha$ function-blocking antibody and in Tnfr1 $1^{-/-}\left(R 1^{--}\right)$mice infected for 14 days. (E) Bronchial lymph node weight in anti-TNF- $\alpha$ antibody-treated WT mice and in infected Tnfr1-/- mice. $P<0.05$, significantly different from $\left(^{*}\right)$ pathogen-free or $(\dagger)$ WT infected groups. Anti-TNF Ab, blocking antibody against mouse TNF- $\alpha$. (F) qRT-PCR measurement of VEGF-A, -C, -D in tracheas of pathogen-free and 14-day infected WT and Tnfr1-/- mice. Expression of VEGF-C, but not VEGF-D is increased in infected WT mice, but not in infected Tnfr $1^{-/-}$mice. VEGF-A expression is not increased in any infected airways. (G-J) H\&E-stained sections of mouse lungs. (G) WT pathogen-free mouse has few H\&E-stained leukocytes in lung parenchyma or airway lumen $\left(^{*}\right)$. (H-J) 14-day M. pulmonis-infected mice. (H) WT untreated mouse has extensive peribronchial cuffing and leukocytes in airway lumen $\left(^{*}\right)$ and lung parenchyma. Leukocyte influx is less prominent in infected WT mouse treated with TNF- $\alpha$ function-blocking antibody (I) and in infected $\operatorname{Tnfr}^{-1-}$ mouse $(\mathbf{J})$. Scale bar: $50 \mu \mathrm{m}$.

were upregulated in airways of infected mice, but expression of VEGF-A was hardly changed. Reduced expression of chemoattractants and adhesion molecules may contribute to the diminished leukocyte influx and lymph node hypertrophy observed in infected mice treated with anti-TNF antibody or deficient
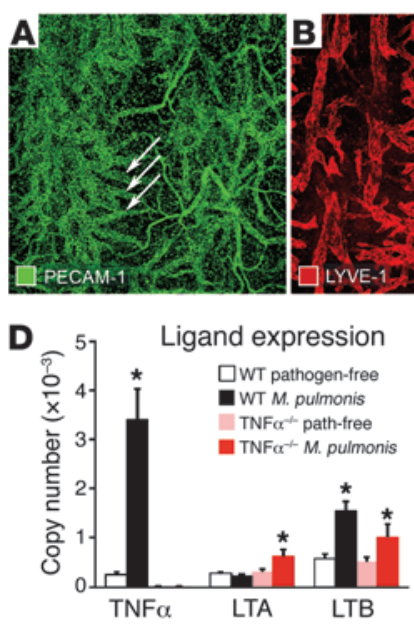
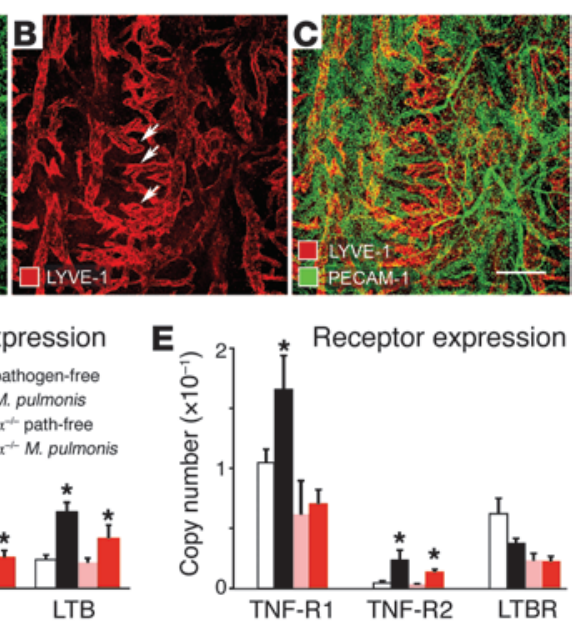

in TNF-R1. Because blood vessel and lymphatic remodeling in M. pulmonis-infected airways depend on the presence of immune cells in the airways (3), the reduced leukocyte influx and production of mediators could account for the reduction in vascular and lymphatic remodeling (38). Others have shown that 
Table 1

Changes in gene expression in mouse tracheas at 3 days of $M$. pulmonis infection relative to pathogen-free state

\begin{tabular}{|c|c|c|c|c|}
\hline \multirow[t]{2}{*}{ Gene name } & \multirow[t]{2}{*}{ Symbol } & \multicolumn{3}{|c|}{ Fold change compared with pathogen-free } \\
\hline & & WT & Tnfr1-1- & $\operatorname{Tnf} \alpha^{-/}$ \\
\hline $\mathrm{Cd} 28$ & $\mathrm{Cd} 28$ & 1.1 & $0.2^{\mathrm{B}}$ & 0.8 \\
\hline $\mathrm{Cd} 38$ & $\mathrm{Cd} 38$ & 1.2 & 1.1 & 2.3 \\
\hline Cd3 antigen, epsilon polypeptide & $C d 3 e$ & 0.6 & 0.3 & 1.4 \\
\hline $\mathrm{Cd} 4$ & $\mathrm{Cd4}$ & 0.2 & 0.3 & ND \\
\hline Cd8 antigen, $\alpha$ chain & Cd8a & 0.2 & 0.05 & 0.1 \\
\hline Cd28 & $\mathrm{Cd} 28$ & 1.1 & 0.2 & 0.8 \\
\hline Cd38 & Cd38 & 1.2 & 1.1 & 2.3 \\
\hline Cd68 (macrosialin) & Cd68 & 1.3 & 2.0 & 2.6 \\
\hline Cd86 (B7-2) & Cd86 & 1.1 & 0.9 & 3.3 \\
\hline Chemokine Ccl2 & $\mathrm{Ccl} 2$ & 13.7 & $1.9^{\mathrm{B}}$ & 15.1 \\
\hline Chemokine Ccl3 & $\mathrm{Ccl3}$ & 114.7 & $16.3^{\mathrm{B}}$ & $7.0^{\mathrm{B}}$ \\
\hline Chemokine Ccl5 & Ccl5 & 1.0 & 1.0 & $7.1^{\mathrm{B}}$ \\
\hline Chemokine Ccl19 & Ccl19 & 3.3 & 2.2 & $6.3^{\mathrm{B}}$ \\
\hline Chemokine Cxcl10 & Cxcl10 & 10.0 & 6.3 & 4.0 \\
\hline Chemokine receptor Ccr2 & Ccr2 & 1.5 & 1.4 & 1.6 \\
\hline Chemokine receptor Ccr7 & Ccr7 & 2.0 & 5.3 & 2.2 \\
\hline Csf2 (granulocyte-macrophage) & Csf2 & 3.5 & $0.2^{\mathrm{B}}$ & 1.5 \\
\hline Complement component 3 & C3 & 3.0 & 1.9 & 1.6 \\
\hline Heme oxygenase & Hmox1 & 1.4 & 0.5 & 3.2 \\
\hline Interleukin-1 $\alpha$ & $\| 11 a$ & 60.8 & $16.0^{B}$ & $1.4^{\mathrm{B}}$ \\
\hline Interleukin-1 $\beta$ & $1 / 1 b$ & 70.1 & $14.4^{\mathrm{B}}$ & $5.0^{B}$ \\
\hline Interleukin-6 & 116 & 15.2 & $0.7^{B}$ & $0.5^{\mathrm{B}}$ \\
\hline Interleukin-10 & $/ / 10$ & 5.1 & $0.7^{\mathrm{B}}$ & ND \\
\hline Interleukin-12 $\alpha$ & $/ 112 a$ & 7.9 & ND & ND \\
\hline Interleukin-12 $\beta$ & $/ / 12 b$ & 3.1 & 1.6 & 0.7 \\
\hline Nitric oxide synthase 2, inducible & Nos2 & 6.3 & $0.9 \mathrm{~B}$ & 6.0 \\
\hline Perforin 1 (pore-forming protein) & Prf1 & 4.7 & $0.7^{\mathrm{B}}$ & $0.3^{\mathrm{B}}$ \\
\hline $\begin{array}{l}\text { Prostaglandin-endoperoxide } \\
\text { synthase } 2 \text { (Cox2) }\end{array}$ & Ptgs2 & 0.7 & 1.3 & 0.6 \\
\hline Selectin, endothelial cell & Sele & 4.2 & $1.8^{\mathrm{B}}$ & 2.3 \\
\hline Selectin, platelet & Selp & 5.1 & $1.6^{\mathrm{B}}$ & 4.6 \\
\hline Stat1 & Stat1 & 2.8 & 2.8 & 2.4 \\
\hline Stat6 & Stat6 & 3.3 & 3.1 & 0.7 \\
\hline Socs2 & Socs2 & 0.6 & 0.9 & $2.5^{\mathrm{B}}$ \\
\hline TNF- $\alpha$ & Tnf & 9.1 & 5.3 & ND \\
\hline TNF receptor superfamily 18 & Tnfrsfo & 0.3 & 0.5 & 0.5 \\
\hline Vcam1 & Vcam1 & 4.2 & 1.3 & 1.2 \\
\hline Vegfa & Vegfa & 1.2 & 0.8 & 0.8 \\
\hline
\end{tabular}

$\mathrm{ND}$, not detected. AFold changes are expressed relative to baseline pathogen-free condition of the same mouse strain, i.e., 1.0 indicates no change; values of more than 1.0 indicate increased expression; and values of less than 1.0 indicate decreased expression. Changes greater than 2-fold from baseline are shown in bold. BValues different in infected Tnfr1 ${ }^{-1-}$ or $\mathrm{Tnf}^{-1-}$ mice compared with WT mice.

airways. Others have reported marked differences in phenotype between Tnf $\alpha^{-/-}$and Tnfr $1^{-/-}$mice, with Tnf $\alpha^{-/-}$ mice much more sensitive to bacterial infection (41-45). It seems that genetic deletion of the ligand is not the same as knocking out the receptor or blocking the ligand pharmacologically. Compensatory pathways presumably develop in $T n \mathrm{fa}^{-1-}$ mice. qRT-PCR showed that expression of lymphotoxin A, a TNF family ligand that signals via TNF receptors, was approximately 2 -fold greater in M. pulmonis-infected Tnf $\alpha^{-/-}$mice than in corresponding WT mice. Whether this increase alone is enough to account for the exaggeration of vascular remodeling remains to be seen.

We reported previously that lymphangiogenesis in airways after $M$. pulmonis infection is driven by effects of VEGF-C and/or VEGF-D on VEGFR-3 signaling (5). However, those studies did not examine the possible role of TNF- $\alpha$ in the induction of the lymphangiogenesis. The apparent lack of TNF-R1 receptors on lymphatic endothelium suggests that the antilymphangiogenic effects of blocking TNF signaling are indirect, involving mediators produced by other cells. For example, TNF- $\alpha$ upregulates expression of VEGF-C (35), a lymphangiogenic growth factor produced by macrophages in infected airways (5). qRT-PCR data showed that VEGF-C expression was lower in infected $\mathrm{Tnfr}^{-/-}$airways.

Blocking TNF signaling was more successful in preventing blood vessel changes and lymphangiogenesis than in reversing them. Rapid and complete reversal of blood vessel changes in M. pulmonis-infected airways is achievable by elimination of the disease by antibiotics (5). Partial reversal occurs after treatment with the antiinflammatory steroid dexamethasone (7). Newly formed lymphatics appear to be more resistant to reversal (5). Together, these observa-

sprouting angiogenesis is reduced by blocking TNF- $\alpha$ pharmacologically (39) or deletion of TNF-R1 $(38,40)$. Interestingly, pathological angiogenesis in oxygen-induced retinopathy does not occur in mice genetically deficient in TNF-R1, but developmental angiogenesis is normal (40). This finding emphasizes the notion that angiogenesis is regulated by different factors under different circumstances.

Initially, we expected genetic deletion of TNF- $\alpha$ to mimic pharmacological blockade of TNF- $\alpha$, as assessed by the magnitude of the response to M. pulmonis infection. Instead, Tnf $\alpha^{-/-}$ mice became much sicker in response to the same infectious dose of organisms, suffered high mortality, and had more vessel remodeling, leukocyte influx, and lymphangiogenesis in the tions suggest that TNF- $\alpha$ may be involved in the initiation of vascular remodeling and lymphangiogenesis after M. pulmonis infection, but other factors are responsible for their maintenance.

Numerous reports show that TNF- $\alpha$ has direct effects on endothelial cells grown in vitro, indicating that signals from associated pericytes or leukocytes are not essential. Our finding of TNF-R1 on endothelial cells of airway blood vessels is consistent with the consensus that most effects of TNF on endothelial cells are mediated by TNF-R1 receptors $(14,46)$, although a minor role for TNF-R2 signaling has also been suggested (47, 48). In our study, blood and lymphatic vessel remodeling, leukocyte influx, and many other consequences of infection were reduced but not eliminated by blocking TNF-R1 signaling. 

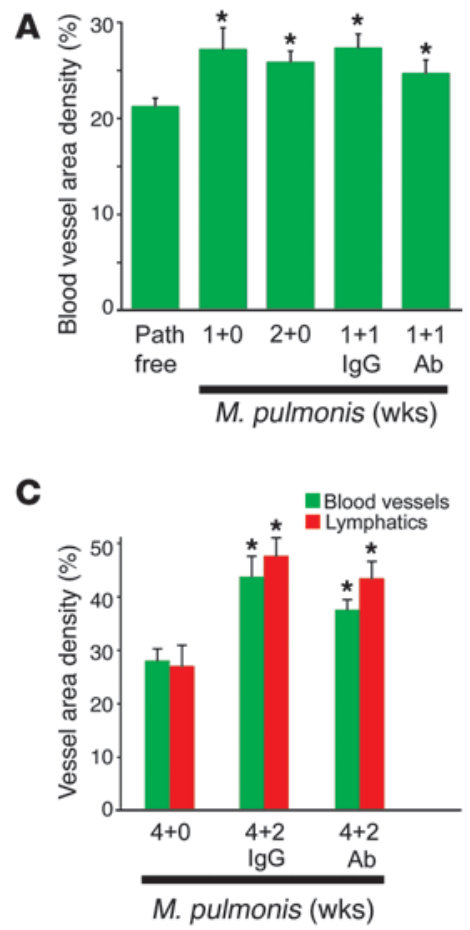

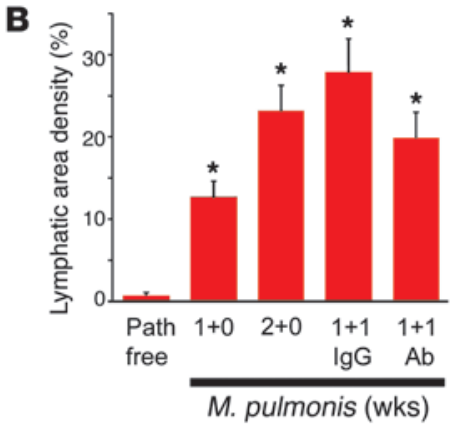

D

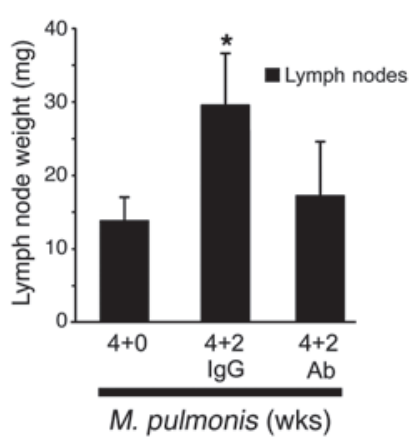

\section{Figure 7}

Lack of reversal of blood vessel remodeling and lymphangiogenesis after TNF- $\alpha$ blockade. Measurements of blood vessels (A) and lymphatics (B) show that area densities increase during the first week after infection. Values for blood vessels reach a plateau, but those for lymphatics increase further during the second week. Anti-TNF- $\alpha$ antibody, given for 1 week beginning 1 week $(1+1)$ after infection tends to reduce further growth of blood vessels or lymphangiogenesis but does not reverse it. Values for lymphatics tend to be less after addition of the anti-TNF- $\alpha$ antibody than after IgG, but the difference is not significant. ${ }^{*} P<0.05$, significantly different from pathogen-free controls. (C) When anti-TNF- $\alpha$ antibody is given for 2 weeks beginning 4 weeks after infection (4+2), blood vessel remodeling and lymphangiogenesis is not significantly different from corresponding values after IgG injected during same period. (D) Weight of bronchial lymph nodes is less after anti-TNF- $\alpha$ antibody than after IgG and is almost reversed to values at the start of anti-TNF- $\alpha$ treatment. ${ }^{*} P<0.05$, significantly different from start of anti-TNF- $\alpha$ treatment ( $n=9-11$ mice per group).
The observations above suggest that TNF- $\alpha$ can trigger other mediators that act downstream or may work synergistically with them. What might be the other mediators? Numerous candidates have been proposed to mediate the angiogenic effects of TNF- $\alpha$, including VEGF, FGF, PDGF, platelet-activating factor, nitric oxide, IL-1, IL-8, and angiopoietins $(39,40,49-53)$. This profusion of potential mediators may reflect the different inflammatory and angiogenic conditions studied. However, 2 downstream pathways deserve special consideration: IL-1 $\beta / \mathrm{IL}-1 \mathrm{R}$ and the angiopoietin/Tie2 pathways.

M. pulmonis infection of airways results in pneumonia-like features, as in respiratory infections by Escherichia coli or Streptococcus aureus, in which TNF- $\alpha$ and IL- $1 \beta$ are expressed together (44, 54). TNF- $\alpha$ and IL- $1 \beta$ are upregulated together in other inflammatory conditions (55). Although TNF- $\alpha$ and IL- $1 \beta$ have distinct receptors, they are induced by similar inflammatory stimuli, share intracellular signaling pathways, notably NF- $\kappa \mathrm{B}$, and induce an overlapping but not identical profile of gene expression $(56,57)$. TNF- $\alpha$ and IL- $1 \beta$ exhibit autoamplification, i.e., they both upregulate their own expression and each other $(56,57)$. In infected lungs, the expression of TNF- $\alpha$ slightly precedes IL- $1 \beta$ (11), suggesting that early expression of TNF- $\alpha$ induces IL-1 $\beta$. Like TNF- $\alpha$, IL-1 $\beta$ can induce angiogenesis in inflammation $(49,52,56)$. Although TNF- $\alpha$ and IL- $1 \beta$ often go hand in hand, they are not always equally potent in inducing angiogenesis, and blocking one mediator can be more effective than blocking the other (58). In the present study, we confirmed that expression of IL- $1 \beta$ was greatly increased in infected airways. Further studies are under way to understand its role.

Angiopoietin/Tie2 signaling is also likely to be involved in mediating effects of TNF signaling on endothelial cells. Among the features that make it attractive, Tie2 receptors are largely confined to endothelial cells (59) and overexpression of Ang1 or Ang2 induces vascular enlargement similar to that observed after M. pulmonis infection (refs. 9, 10; J. Fuxe, unpublished observations). Blocking Tie 2 with a soluble antagonist reduces the angio- genesis induced by TNF- $\alpha$ in the mouse cornea, and overexpression of Ang1 or Ang2 potentiates it $(39,53)$. Furthermore, TNF- $\alpha$ upregulates expression of Ang1, Ang2, and Tie2 in endothelial cells (60-65). Further studies are underway to understand how Ang/Tie2 signaling is involved in mediating the vascular changes observed after $M$. pulmonis infection.

Blocking TNF- $\alpha$ signaling would seem to be among the logical approaches for treating airway diseases such as severe asthma and chronic obstructive pulmonary disease (66). Recent clinical studies of asthmatics treated with anti-TNF- $\alpha$ therapy have found improved lung function and quality of life and reduced airway hyperresponsiveness and exacerbation (67-69).

More than a century ago, Robert Koch put forward postulates that must be fulfilled to implicate a particular microbe as the cause of a specific disease. TNF- $\alpha$ compellingly satisfies the equivalents of Koch's postulates as a causal factor for the special type of angiogenesis manifested as vascular enlargement in inflamed tissues. TNF- $\alpha$ is present and is increased in inflammation with a time course similar to the vascular changes; its receptors are present on endothelial cells, and the vascular changes induced by disease are inhibited when TNF signaling is blocked. Moreover, TNF- $\alpha$ can increase the production of downstream molecules that have potent actions on endothelial cells.

\section{Methods}

Mice. Specific pathogen-free WT C57BL/6 mice (Charles River) of either sex were housed under barrier conditions before and after infection. Tnfr $1^{-/-}$ mice on a C57BL/6 background (70) or Tnfa $\mathrm{\alpha}^{-/-}$mice and WT controls (strain 101045 ) on a mixed 129/C57BL/6 background (41) were purchased from Jackson Laboratories. Mice were anesthetized by intramuscular injection of ketamine $(87 \mathrm{mg} / \mathrm{kg})$ and xylazine $(13 \mathrm{mg} / \mathrm{kg})$. The Institutional Animal Care and Use Committees of UCSF approved all experimental procedures.

M. pulmonis infection. Mice were infected by intranasal inoculation of $50 \mu \mathrm{l}$ of broth containing $10^{6} \mathrm{CFU}$ of M. pulmonis organisms of strain CT7 
(5). The severity of infection was assessed at the end of the experiment by weighing bronchial lymph nodes and lungs and by examining H\&Estained $3-\mu \mathrm{m}$ sections of the left lung, which was usually more severely affected. In some cases, the bacterial burden was estimated by measuring gene expression of $M$. pulmonis-specific $16 \mathrm{~S}$ rRNA. The infection continued throughout the time course of the experiments.

Blockade of TNF- $\alpha$ signaling. To determine whether vascular changes could be prevented, WT mice received the first $100-\mu \mathrm{g}$ dose of a chimeric rat/mouse monoclonal anti-mouse TNF- $\alpha$ function-blocking antibody (CNTO2213; Centocor Research and Development Inc.; ref. 71) or an isotype-matched control rat IgG injected intraperitoneally and immediately thereafter were infected with $M$. pulmonis. Subsequent doses of antibody were injected every other day for up to 14 days. This dose of anti-TNF- $\alpha$ antibody effectively neutralizes TNF- $\alpha$ in mice $(72,73)$. To test the reversibility of vascular remodeling, mice were infected for 1 week and then treated with anti-TNF- $\alpha$ antibody for the second week or infected for 4 weeks and then treated with the antibody for 2 weeks.

Immunohistochemistry. After anesthesia, the vasculature was perfused for 2 minutes with fixative (1\% paraformaldehyde in PBS, pH 7.4) from a cannula inserted through the left ventricle into the aorta. Tracheas, bronchial lymph nodes, and lungs were removed and immersed in fixative for 1 hour at $4^{\circ} \mathrm{C}$. Bronchial lymph nodes and lungs were weighed to assess the overall severity of disease and leukocyte trafficking. Tissues were washed and stained immunohistochemically by incubating 80 - $\mu \mathrm{m}$-thick cryostat sections or whole mounts with 1 or more of the following primary antibodies diluted in PBS containing $0.3 \%$ Triton X-100, $0.2 \%$ BSA, $5 \%$ normal serum, and $0.1 \%$ sodium azide, as described previously (5); endothelial cells (both vascular and lymphatic): CD31 (hamster anti-mouse, clone 2H8, Fisher; or rat anti-mouse clone MEC13.3, BD Biosciences), VE-cadherin, and MECA-32 (rat anti-mouse, clones 11D4.1 and MECA-32; BD Biosciences); dividing nuclei: phosphohistone H3 (rabbit polyclonal; Upstate Biotechnology); lymphatics: LYVE-1 (rabbit polyclonal antibodies; Upstate Biotechnology or AngioBio or rat monoclonal antibody; R\&D Systems); macrophages and dendritic cells: Iba1 (rabbit polyclonal 01919741; Wako); pericytes and smooth muscle cells: rabbit polyclonal antibodies to NG2 (Chemicon) and desmin (Dako); leukocytes: CD11b or CD45 (rat clones Ly-5; BD Biosciences); TNF- $\alpha$, TNF-R1, TNF-R2, and LTBR (goat polyclonal antibodies; R\&D Systems). In cases in which the epithelium stained strongly (TNF-R1 and LTBR) and prevented clear viewing of underlying vessels by fluorescence microscopy, we stained flattened tracheal whole mounts and made 3D Z-stack confocal projections of the mucosa, which made it possible to subtract the signal from confocal slices containing the epithelium. Secondary antibodies were labeled with FITC, Cy3, or Cy5 (Jackson ImmunoResearch). Specimens were viewed with a Zeiss Axiophot fluorescence microscope equipped with a video camera or a Zeiss LSM510 confocal microscope using AIM 3.2.2 confocal software. Some lungs were prepared for H\&E staining.

Morphometric measurements. Vessel diameter and length, width, and mucosal area occupied by blood vessels and lymphatics were measured in realtime images of tracheas stained for CD31 and LYVE- 1 by using a digitizing tablet linked to a video camera on a Zeiss Axiophot microscope with $\times 10$, NA 0.5 , or $\times 20$, NA 0.75 , objectives (5). Area densities for blood vessels and lymphatics were calculated for regions of the mucosa overlying the tracheal cartilage rings, where the greatest changes occurred.

qRT-PCR. Mice were anesthetized and briefly perfused via the aorta with sterile PBS. Tracheas were removed and stored in RNAlater reagent and homogenized; total RNA was extracted using RNeasy Fibrous Tissue kit (QIAGEN). cDNA was generated using random primers (Invitrogen) and Moloney Murine Leukemia Virus Reverse Transcriptase (Invitrogen). Samples of $1 \mathrm{ng}$ cDNA were subjected to RT-PCR using SYBR Green protocols and ER qPCR SuperMix Universal (Invitrogen). Primers were designed using data from PrimerBank (http://pga.mgh.harvard.edu/primerbank) or pub- lished sequences from the literature. The forward and reverse primers were as follows: $\beta$-actin, $5^{\prime}$-GAAGCTGTGCTATGTTGCTCTA-3' and 5'-GGAGGAAGAGGATGCGGCA-3'; LTA, 5'-GACTCTCTGGTGTCCGCTTCT$3^{\prime}$ and $5^{\prime}$-GGTACCCAACAAGGTGAGCAG-3'; LTB, 5'-GGACGTCGGGTTGAGAAGA-3' and 5'-CGGTTTGCTGTCATCCAGTC-3'; LTBR, 5'-AAGCCGGGACACTTCCAGA-3' and 5'-AGATGGTATCCGAGTAGGAGGT-3'; M. pulmonis 16S rRNA, 5'-CGGTACAGGAAACTGTTGCTAATACCG- $3^{\prime}$ and $5^{\prime}$-CCATTTCAAAGTGAAGCAAACG-3'; TNF- $\alpha, 5^{\prime}$-CCACCACGCTCTTCTGTCTAC-3' and 5'-AGGGTCTGGGCCATAGAACT- $3^{\prime}$; TNF-R1, 5'-AGAACCAGTTCCAACGCTACC-3' and 5'-TCTGAGTCTCCTTACAGGGGAT-3'; TNF-R2, 5'-CAGGTTGTCTTGACACCCTAC-3' and $5^{\prime}$-GCACAGCACATCTGAGCCT-3'; VEGF-A, 5'-CTGCCGTCCGATTGAGACC-3' and 5'-CCCCTCCTTGTACCACTGTC-3'; VEGF-C, 5'-GCAAGACGAGACTCCACTGC-3' and 5'-GGGAGATCTCATTCAGCACC-3'; and VEGF-D, 5'-TCACGCTCAGCATCCCATC-3' and 5'-ACTTCTACGCATGTCTCTCTAGG-3'. RT-PCR analysis was done using Chromo4 or MyiQ RT-PCR machines (Bio-Rad). Samples were measured in duplicate, and values were normalized to $\beta$-actin. Results are presented as fold increases of mRNA or number of copies relative to $\beta$-actin. However, since infected airways increased in weight due to the large influx of leukocytes, the mRNA for some genes may have been diluted by the increased tissue mass, which would result in underestimation of expression.

Gene profiling by TaqMan gene array. RNA was extracted from samples as above and measured using a NanoDrop 8000 spectrophotometer (Thermo Fisher Scientific). RNA quality was verified on the Agilent 2100 Bioanalyzer (Agilent Technologies). For RT-PCR, 800 ng of cDNA was prepared using the iScript cDNA synthesis kit (Bio-Rad). The cDNA was applied to TaqMan RT-PCR Mouse Immune Array microfluidic cards (47365297; Applied Biosystems) and run on the Applied Biosystems 7900HT Fast RealTime PCR system; data were analyzed using the $\Delta \delta C T$ method as described in the manufacturer's protocol. Samples were tested with 3-4 specimens per group, and relative gene expression data were normalized to $\beta$-actin. Results are presented as fold increases of mRNA in infected groups relative to corresponding pathogen-free controls.

Statistics. Values are presented as means \pm SEM with 4-5 mice per group unless otherwise indicated. The significance of differences between means was assessed by ANOVA followed by Dunn-Bonferroni's test for multiple comparisons, with $P<0.05$ considered significant.

\section{Acknowledgments}

This work was supported in part by grants from the US National Heart, Lung, and Blood Institute (HL-24136 and HL-59157) and from the National Cancer Institute (CA-82923). We thank Sebastien Tabruyn (UCSF), Nancy Ruddle and Rawad Mounzer (Yale University), and Linda Snyder (Centocor Research and Development Inc.) for helpful discussions and critical reading of the manuscript. We thank Carolyn Woo for help with measurements of blood vessel size, Nigel Killeen for use of the Chromo4 RT-PCR machine in his laboratory, and DongJi Zhang for preparing stocks of $M$. pulmonis organisms.

Received for publication October 1, 2008, and accepted in revised form July 15, 2009.

Address correspondence to: Peter Baluk, University of California, 513 Parnassus Avenue, San Francisco, California 94143-0130, USA. Phone: (415) 476-2118; Fax: (415) 476-4845; E-mail: peter. baluk@ucsf.edu.

Li Yan's present address is: Clinical Oncology, Merck \& Co. Inc., North Wales, Pennsylvania, USA. 
1. Thurston, G., Murphy, T.J., Baluk, P., Lindsey, J.R., and McDonald, D.M. 1998. Angiogenesis in mice with chronic airway inflammation: strain-dependent differences. Am. J. Pathol. 153:1099-1112.

2. Thurston, G., Baluk, P., and McDonald, D.M. 2000 Determinants of endothelial cell phenotype in venules. Microcirculation. 7:67-80.

3. Aurora, A.B., et al. 2005. Immune complex-dependent remodeling of the airway vasculature in response to a chronic bacterial infection. J. Immunol. 175:6319-6326.

4. Baluk, P., et al. 2007. Functionally specialized junctions between endothelial cells of lymphatic vessels. J. Exp. Med. 204:2349-2362.

5. Baluk, P., et al. 2005. Pathogenesis of persistent lymphatic vessel hyperplasia in chronic airway inflammation. J. Clin. Invest. 115:247-257.

6. Baluk, P., et al. 2004. Regulated angiogenesis and vascular regression in mice overexpressing vascular endothelial growth factor in airways. Am. J. Pathol. 165:1071-1085.

7. Thurston, G., Maas, K., Labarbara, A., McLean, J.W., and McDonald, D.M. 2000. Microvascular remodelling in chronic airway inflammation in mice. Clin. Exp. Pharmacol. Physiol. 27:836-841.

8. Ezaki, T., et al. 2001. Time course of endothelial cell proliferation and microvascular remodeling in chronic inflammation. Am. J. Pathol. 158:2043-2055.

9. Thurston, G., et al. 2005. Angiopoietin 1 causes vessel enlargement, without angiogenic sprouting, during a critical developmental period. Development. 132:3317-3326.

10. Kim, K.E., et al. 2007. In vivo actions of angiopoietins on quiescent and remodeling blood and lymphatic vessels in mouse airways and skin. Arterioscler. Thromb. Vasc. Biol. 27:564-570.

11. Faulkner, C.B., et al. 1995. Gene expression and production of tumor necrosis factor alpha, interleukin 1 , interleukin 6 , and gamma interferon in $\mathrm{C} 3 \mathrm{H} / \mathrm{HeN}$ and C57BL/6N mice in acute Mycoplasma pulmonis disease. Infect. Immun. 63:4084-4090.

12. Lewis, C.C., et al. 2008. Disease-specific gene expression profiling in multiple models of lung disease. Am. J. Respir. Crit. Care Med. 177:376-387.

13. Sun, X., Jones, H.P., Hodge, L.M., and Simecka, J.W. 2006. Cytokine and chemokine transcription profile during Mycoplasma pulmonis infection in susceptible and resistant strains of mice: macrophage inflammatory protein 1beta (CCL4) and monocyte chemoattractant protein 2 (CCL8) and accumulation of CCR5+ Th cells. Infect. Immun. 74:5943-5954.

14. Chen, G., and Goeddel, D.V. 2002. TNF-R1 signaling: a beautiful pathway. Science. 296:1634-1635.

15. Locksley, R.M., Killeen, N., and Lenardo, M.J. 2001. The TNF and TNF receptor superfamilies: integrating mammalian biology. Cell. 104:487-501.

16. Madge, L.A., and Pober, J.S. 2001. TNF signaling in vascular endothelial cells. Exp. Mol. Pathol. 70:317-325.

17. Ware, C.F. 2003. The TNF superfamily. Cytokine Growth Factor Rev. 14:181-184.

18. Frater-Schroder, M., Risau, W., Hallmann, R., Gautschi, P., and Bohlen, P. 1987. Tumor necrosis factor type alpha, a potent inhibitor of endothelial cell growth in vitro, is angiogenic in vivo. Proc. Natl. Acad. Sci. U. S. A. 84:5277-5281.

19. Leibovich, S.J., et al. 1987. Macrophage-induced angiogenesis is mediated by tumour necrosis factor-alpha. Nature. 329:630-632.

20. Cho, C.H., et al. 2007. Angiogenic role of LYVE-1positive macrophages in adipose tissue. Circ. Res. 100:e47-e57.

21. Maruyama, K., et al. 2005. Inflammation-induced lymphangiogenesis in the cornea arises from CD11b-positive macrophages. J. Clin. Invest. 115:2363-2372.

22. Grigorova, I.L., et al. 2009. Cortical sinus probing,
S1P1-dependent entry and flow-based capture of egressing T cells. Nat. Immunol. 10:58-65.

23. Kohler, C. 2007. Allograft inflammatory factor1 /Ionized calcium-binding adapter molecule 1 is specifically expressed by most subpopulations of macrophages and spermatids in testis. Cell Tissue Res. 330:291-302.

24. Carmeliet, P. 2000. Mechanisms of angiogenesis and arteriogenesis. Nat. Med. 6:389-395.

25. Gerhardt, H., et al. 2003. VEGF guides angiogenic sprouting utilizing endothelial tip cell filopodia. J. Cell Biol. 161:1163-1177.

26. Djonov, V., Baum, O., and Burri, P.H. 2003. Vascular remodeling by intussusceptive angiogenesis. Cell Tissue Res. 314:107-117.

27. Helisch, A., et al. 2006. Impact of mouse strain differences in innate hindlimb collateral vasculature. Arterioscler. Thromb. Vasc. Biol. 26:520-526.

28. Heil, M., Eitenmuller, I., Schmitz-Rixen, T., and Schaper, W. 2006. Arteriogenesis versus angiogenesis: similarities and differences. J. Cell. Mol. Med. 10:45-55.

29. Rogers, M.S., Rohan, R.M., Birsner, A.E., and D’Amato, R.J. 2003. Genetic loci that control vascular endothelial growth factor-induced angiogenesis. FASEB J. 17:2112-2114.

30. Rohan, R.M., Fernandez, A., Udagawa, T., Yuan, J., and D'Amato, R.J. 2000. Genetic heterogeneity of angiogenesis in mice. FASEB J. 14:871-876.

31. Lindsey, J., et al. 1991. Infectious diseases of mice and rats. National Academy of Sciences. Washington, DC, USA. 397 PP.

32. Lindsey, J.R., Baker, H.J., Overcash, R.G., Cassell, G.H., and Hunt, C.E. 1971. Murine chronic respiratory disease. Significance as a research complication and experimental production with Mycoplasma pulmonis. Am. J. Pathol. 64:675-708.

33. Schoeb, T., Davis, J., and Lindsey, J. 1996. Murine respiratory mycoplasmosis, rat and mouse. In Monographs on the pathology of laboratory animals. Respiratory system. T. Jones, D. Dungworth, and U. Mohr, editors. Springer Verlag. New York, New York, USA. 117-131.

34. Ghosh, S., and Karin, M. 2002. Missing pieces in the NF-kappaB puzzle. Cell. 109(Suppl.):S81-S96.

35. Ristimaki, A., Narko, K., Enholm, B., Joukov, V., and Alitalo, K. 1998. Proinflammatory cytokines regulate expression of the lymphatic endothelial mitogen vascular endothelial growth factor-C. J. Biol. Chem. 273:8413-8418.

36. Viemann, D., et al. 2004. Transcriptional profiling of IKK2/NF-kappa B- and p38 MAP kinase-dependent gene expression in TNF-alpha-stimulated primary human endothelial cells. Blood. 103:3365-3373.

37. Aggarwal, B.B. 2003. Signalling pathways of the TNF superfamily: a double-edged sword. Nat. Rev. Immunol. 3:745-756.

38. Barcelos, L.S., et al. 2005. Impaired inflammatory angiogenesis, but not leukocyte influx, in mice lacking TNFR1. J. Leukoc. Biol. 78:352-358.

39. DeBusk, L.M., et al. 2003. Tie2 receptor tyrosine kinase, a major mediator of tumor necrosis factor alpha-induced angiogenesis in rheumatoid arthritis. Artbritis Rheum. 48:2461-2471.

40. Kociok, N., Radetzky, S., Krohne, T.U., Gavranic, C., and Joussen, A.M. 2006. Pathological but not physiological retinal neovascularization is altered in TNF-Rp55-receptor-deficient mice. Invest. Ophthalmol. Vis. Sci. 47:5057-5065.

41. Pasparakis, M., Alexopoulou, L., Episkopou, V., and Kollias, G. 1996. Immune and inflammatory responses in TNF alpha-deficient mice: a critical requirement for TNF alpha in the formation of primary B cell follicles, follicular dendritic cell networks and germinal centers, and in the maturation of the humoral immune response. J. Exp. Med. 184:1397-1411.

42. Marino, M.W., et al. 1997. Characterization of tumor necrosis factor-deficient mice. Proc. Natl. Acad. Sci. U. S. A. 94:8093-8098.

43. Mizgerd, J.P., Peschon, J.J., and Doerschuk, C.M. 2000. Roles of tumor necrosis factor receptor signaling during murine Escherichia coli pneumonia. Am. J. Respir. Cell Mol. Biol. 22:85-91.

44. Mizgerd, J.P., Spieker, M.R., and Doerschuk, C.M. 2001. Early response cytokines and innate immunity: essential roles for TNF receptor 1 and type I IL-1 receptor during Escherichia coli pneumonia in mice. J. Immunol. 166:4042-4048.

45. Lee, J.H., et al. 2003. Modulation of bacterial growth by tumor necrosis factor-alpha in vitro and in vivo. Am. J. Respir. Crit. Care Med. 168:1462-1470.

46. Pober, J.S. 2002. Endothelial activation: intracellular signaling pathways. Arthritis Res. 4(Suppl. 3):S109-S116.

47. He, Y., et al. 2006. Critical function of Bmx/Etk in ischemia-mediated arteriogenesis and angiogenesis. J. Clin. Invest. 116:2344-2355.

48. Zhang, R., et al. 2003. Etk/Bmx transactivates vascular endothelial growth factor 2 and recruits phosphatidylinositol 3-kinase to mediate the tumor necrosis factor-induced angiogenic pathway. J. Biol. Chem. 278:51267-51276.

49. Fan, T.P., Hu, D.E., Guard, S., Gresham, G.A., and Watling, K.J. 1993. Stimulation of angiogenesis by substance $P$ and interleukin-1 in the rat and its inhibition by NK1 or interleukin-1 receptor antagonists. Br. J. Pharmacol. 110:43-49.

50. Yoshida, S., et al. 1997. Involvement of interleukin8 , vascular endothelial growth factor, and basic fibroblast growth factor in tumor necrosis factor alpha-dependent angiogenesis. Mol. Cell. Biol. 17:4015-4023.

51. Montrucchio, G., et al. 1997. Nitric oxide mediates angiogenesis induced in vivo by platelet-activating factor and tumor necrosis factor-alpha. Am.J. Pathol. 151:557-563.

52. Dana, M.R., Zhu, S.N., and Yamada, J. 1998. Topical modulation of interleukin-1 activity in corneal neovascularization. Cornea. 17:403-409.

53. Chen, J.X., Chen, Y., DeBusk, L., Lin, W., and Lin, P.C. 2004. Dual functional roles of Tie-2/angiopoietin in TNF-alpha-mediated angiogenesis. Am. J. Physiol. Heart Circ. Physiol. 287:H187-H195.

54. Jones, M.R., Simms, B.T., Lupa, M.M., Kogan, M.S., and Mizgerd, J.P. 2005. Lung NF-kappaB activation and neutrophil recruitment require IL-1 and TNF receptor signaling during pneumococcal pneumonia. J. Immunol. 175:7530-7535.

55. Pober, J.S., et al. 1986. Two distinct monokines, interleukin 1 and tumor necrosis factor, each independently induce biosynthesis and transient expression of the same antigen on the surface of cultured human vascular endothelial cells. J. Immunol. 136:1680-1687.

56. Mantovani, A., Bussolino, F., and Dejana, E. 1992. Cytokine regulation of endothelial cell function. FASEB J. 6:2591-2599.

57. Taberner, M., et al. 2005. Overlapping gene expression profiles in rheumatoid fibroblast-like synoviocytes induced by the proinflammatory cytokines interleukin-1 beta and tumor necrosis factor. Inflamm. Res. 54:10-16.

58. Coxon, A., et al. 2002. Inhibition of interleukin-1 but not tumor necrosis factor suppresses neovascularization in rat models of corneal angiogenesis and adjuvant arthritis. Arthritis Rheum. 46:2604-2612.

59. Yancopoulos, G.D., et al. 2000. Vascular-specific growth factors and blood vessel formation. Nature. 407:242-248.

60. Kim, I., Kim, J.H., Ryu, Y.S., Liu, M., and Koh, G.Y. 2000. Tumor necrosis factor-alpha upregulates angiopoietin-2 in human umbilical vein endothelial cells. Biochem. Biophys. Res. Commun. 269:361-365.

61. Willam, C., et al. 2000. Tie2 receptor expression is stimulated by hypoxia and proinflammatory 
cytokines in human endothelial cells. Circ. Res. 87:370-377.

62. Brown, C., et al. 2004. ESE-1 is a novel transcriptional mediator of angiopoietin-1 expression in the setting of inflammation. J. Biol. Chem. 279:12794-12803.

63. Fiedler, U., et al. 2004. The Tie-2 ligand angiopoietin- 2 is stored in and rapidly released upon stimulation from endothelial cell Weibel-Palade bodies. Blood. 103:4150-4156.

64. Hegen, A., et al. 2004. Expression of angiopoietin2 in endothelial cells is controlled by positive and negative regulatory promoter elements. Arterioscler. Thromb. Vasc. Biol. 24:1803-1809.

65. Fiedler, U., et al. 2006. Angiopoietin-2 sensitizes endothelial cells to TNF-alpha and has a crucial role in the induction of inflammation. Nat. Med. 12:235-239.

66. Barnes, P.J. 2003. Cytokine-directed therapies for the treatment of chronic airway diseases. Cytokine Growth Factor Rev. 14:511-522.

67. Berry, M., Brightling, C., Pavord, I., and Wardlaw, A. 2007. TNF-alpha in asthma. Curr. Opin. Pharmacol. 7:279-282.

68. Berry, M.A., et al. 2006. Evidence of a role of tumor necrosis factor alpha in refractory asthma. $N$. Engl. J. Med. 354:697-708.

69. Erin, E.M., et al. 2006. The effects of a monoclonal antibody directed against tumor necrosis factor-alpha in asthma. Am. J. Respir. Crit. Care Med.
174:753-762.

70. Peschon, J.J., et al. 1998. TNF receptor-deficient mice reveal divergent roles for $\mathrm{p} 55$ and $\mathrm{p} 75$ in several models of inflammation. J. Immunol. 160:943-952.

71. Shealy, D.J., and Visvanathan, S. 2008. Anti-TNF antibodies: lessons from the past, roadmap for the future. Handb. Exp. Pharmacol. 181:101-129.

72. Kadokami, T., Frye, C., Lemster, B., Wagner, C.L., Feldman, A.M., and McTiernan, C.F. 2001. Antitumor necrosis factor-alpha antibody limits heart failure in a transgenic model. Circulation. 104:1094-1097.

73. Scott, K.A., et al. 2003. An anti-tumor necrosis factoralpha antibody inhibits the development of experimental skin tumors. Mol. Cancer Ther. 2:445-451. 